\title{
О ЗАНАВЕСИ (СКРЫТЫХ СМЫСЛАХ) В КУЛЬТУРЕ И ИСКУССТВЕ
}

\author{
А. А. Атанов \\ Байкальский государственный университет, г. Иркутск, Российская Федерация
}

Информация о статье

Дата поступления

25 декабря 2017 г.

Дата принятия к печати

28 фревраля 2018 г.

Дата онлайн-размещения 30 марта 2018 г.

\author{
Ключевые слова \\ Искусство; культура; \\ произведение; миф; \\ Ф. М. Достоевский; \\ Ж.-П. Сартр; Афрродита; тень; \\ смысл; Библия; тотем; основа; \\ занавесь; занавеска
}

\begin{abstract}
Аннотация
В статье рассматриваются неочевидные формы прочтения смыслов культуры и искусства, связанные со спецификой человеческой природы и особенностями человеческого восприятия. Анализируются мифы Древней Греции, библейские тексты, произведения Ф. М. Достоевского, Л. Н. Толстого, Ж.-П. Сартра. Акцент в проводимом анализе делается на смещение восприятия смысла произведения в зависимости от предпочтений автора, а также на фиксацию подлинного смысла исходя из позиции наблюдателя, где все смещения становятся актуальными и отслеживаемыми.
\end{abstract}

\section{CONCERNING THE «CURTAIN» (HIDDEN MEANINGS) IN CULTURE AND ART}

\author{
Andrei A. Atanov \\ Baikal State University, Irkutsk, the Russian Federation
}

\section{Article info}

Received

December 25, 2017

Accepted

February 28, 2018

Available online

March 30, 2018

\section{Keywords}

Art; culture; piece of work; myth; Fyodor Dostoevsky; JeanPaul Sartre; Aphrodite; shadow; meaning; Bible; totem; basis: curtain; drape

\begin{abstract}
The article covers unmanifest forms of culture and art meanings interpretation, regarding the specifics of human nature and perception. The myths of Ancient Greece, biblical texts, masterpieces of Fyodor Dostoevsky, Leo Tolstoy and Jean-Paul Sartre are analyzed. The emphasis of the analysis is placed on the perception shift, regarding the author's preferences, and the true meaning fixation from the perspective of an observer, where all the shifts become sought out and traceable.
\end{abstract}

Когда исследуется культура и искусство, весьма часто мы соприкасаемся с закрытыми, спрятанными темами. На первый взгляд явление одно, но на самом деле совершенно другое, особенно если мы становимся на позицию наблюдателя, а не следуем за мнением или эмоциональными суждениями автора. Эмоции могут быть рассмотрены как объект анализа. Действительность, соотнесенная с конкретной эмоцией, выглядит иначе, чем когда она соотнесена с другой эмоцией. Образ, произведение, артефакт в системе человеческого опыта движутся, занимают неравное себе положение. Логика этого движения или смещения зачастую ускользает от самого создателя произведения, в результате произведение начинает рассказывать о том, о чем бы его создатель хотел промолчать. Специфика человеческой природы связана в том числе с темой «прятанья», а потом проговаривания или рассказа о том, что спрятано.

В искусстве любят и ценят тему занавесей. Занавесь скрывает, прячет, помогает спрятаться, но наличие занавеси всегда про присутствие - явное или тайное. Спрятался 
сам за занавес или спрятались за него другие - это не тема тайны, а тема пребывания здесь и сейчас в качестве вроде бы условного Я, но на самом деле всегда в присутствии другого.

В Ветхом Завете есть приписываемая царю Соломону книга Когелет, что на русский язык переводится как «проповедник». Последуем за логикой наблюдения. Если ты самый мудрый из людей, тогда у тебя гигантская тень (связанная со знанием не только видимой, но и скрытой стороны вещей), ведь нужно знать не только то, что под солнцем, но и то, что сокрыто от солнечных лучей. Иначе у тебя нет целостного восприятия действительности, и мудрость твоя будет однобокой, определяемой твоими убеждениями. Если вспомнить, что исторический царь Соломон освободил колено Иуды, из которого сам происходил, от уплаты налогов, то история целостности становится совершенно иной, включающей в себя тему личных предпочтений, а не тему сохранения царства. Вскоре после смерти Соломона царство распалось на Израиль и Иудею. Это не тема мудрости, а тема своего - чужого. Тогда проповедник все-таки не царь, а проповедник, человек, скрывающийся за этим именем, неизвестен, но он уплатил свою цену за мудрость. У всего есть цена, у мудрости это знание оборотной стороны жизни, и если ты не учитываешь эту сторону независимо от того, нравится она тебе или не нравится, ты просто глуп.

Посмотрим, как эта тема развита в искусстве. У Ж.-П. Сартра царь Эгисф платит за полученное царство. Его главное желание это желание умереть. Приведем цитату из пьесы Сартра «Мухи»: «Юпитер. Не преувеличивай! Ты здоров и толст! Впрочем, это я не в упрек тебе. Отличный царский жир, желтый, как свечное сало, так и надо. Ты скроен, чтоб прожить еще двадцать лет.

$<\ldots>$

...И, однако, ах ты, дурачок, коняшка, гадкий маленький коняшка, сердцем ты ведь давно сказал мне: да...» [1, с. 233-234]. Эгисфра мучают воспоминания о том, как он бежал с топором к ванне, где был Агамемнон, но на этом все не закончилось, нужно было рубить топором Агамемнона. Цена царства. Юпитер и говорит о царском жире, о сердце - не о внешнем, а о внутреннем. Единство внешнего и внутреннего есть логическое проявление основы.

В любом произведении мы улавливаем дополнительные смыслы, о которых умалчивает автор, но эти смыслы есть, и они влияют не только на восприятие произведения, но и на его реальную структуру. В результате история, рассказываемая автором, становится совершенно другой, ведь даже фигуры умолчания говорят об очень многом. Вспомним любимое революционными демократами и В. Белинским произведение Ф. М. Достоевского «Бедные люди» и проанализируем его без предвзятости. Его герой - Макар Девушкин, чиновник, получающий жалованье. Тема нищеты, педалируемая Достоевским, в этом контексте выглядит несколько двусмысленно. Макар Девушкин решил заняться сочинительством, его адресат - молоденькая прехорошенькая барышня. Вот как сам Достоевский описывает приготовления Девушкина: «... Свечку достал, приготовляю бумаги, чиню перо, вдруг, невзначай, подымаю глаза, - право, у меня сердце вот так и запрыгало! Так вы-таки поняли, чего мне хотелось, чего сердчишку моему хотелось! Вижу, уголочек занавески у окна вашего загнут и прицеплен к горшку с бальзамином, точнехонько так, как я вам тогда намекал; тут же показалось мне, что и личико ваше мелькнуло у окна, что и вы ко мне из комнаты вашей смотрели, что вы обо мне думали» [2, с. 3]. Интересно, о чем это Девушкин? Вернемся к Сартру и услышим вполне ясно проговариваемые темы, которые потом тщательно прячут от себя «добрые» «бедные» люди.

Ситуация относится к моменту убийства Эгисором Агамемнона. Мы рассказали, как ситуация воспринимается Юпитером, но с учетом переживаний Эгисфа. Теперь та же ситуация убийства Агамемнона, рассказываемая наблюдателем Юпитером, проследившим за одной подданной тогда еще царя Агамемнона, ныне подданной царя Эгисфа.

«Старуха. Как я могла поступить? Мой муж работал на поле, я задвинула все засовы.

Юпитер. Да, и приоткрыла окно, чтобы лучше слышать, притаилась за занавеской, дыханье у тебя перехватывало, в животе сладко щекотало.

Старуха. Замолчи.

Юпитер. Ох и жаркая ж у вас была в ту ночь любовь. Вот праздник-то был, а?

С таруха. О! Господи... жуткий праздник.

Юпитер. Багряный праздник, вы так и не смогли похоронить память о нем.

С таруха. Господи! Вы из мертвецов?

Юпитер. Мертвец! Ступай, ступай, безумная. Не твое это дело, кто я. Подумай лучше о себе, о том, как вымолить прощенье неба покаяньем.

Старуха. О, я каюсь, господи, если бы вы знали, как я каюсь. И моя дочь тоже 
кается, и зять ежегодно приносит корову в жертву; и внука, которому седьмой год, мы приучили к покаянию. Он послушен как овечка, весь беленький и уже исполнен чувства первородного греха.

Юпитер. Это хорошо. Убирайся, старая паскуда, смотри не сдохни без покаяния. В нем вся твоя надежда на спасение» [1, C. 201-202].

Интересно, каются ли те, кто не совокуплялся, не замирал за занавеской, не слышал криков царя? Судя по всему, каются все. Как вам в этом контексте «бедный» Макар Девушкин с его свечой и занавесочкой? До чувства вины он просто не дорос, но страстишки играют. Страстишки внутренние, а не внешние. К чему или к кому они могут устремиться?

У А. Пекуровской есть очень точная ремарка, относящаяся к еще одному «доброму» человеку русской литературы, князю Мышкину: «...а Парфену Рогожину, мазохистскому партнеру и убийце Настасьи Филипповны, еще предстоит приоткрыть уголок занавески, а точнее, приподнять край шторы, чтобы убедиться в том, что под окнами стоит подстрекатель этого убийства и будущий свидетель князь Мышкин» [3, с. 62].

Посмотрим на еще одного «бедного» героя Достоевского Прохарчина глазами выдающегося ученого В. Н. Топорова. Прохарчин «самоопределяет себя - постоянно, последовательно, весьма изобретательно... именно как бедняка, т. е. ниже, чем то, на что он мог бы претендовать, имея чиновническое жалованье (не говоря уже о его накоплениях, скрытых для внешнего наблюдателя), причем видит гарантии социальной устойчивости и ее безопасности не в богатстве, а как раз в сокрытии его» [4, с. 132]. Очень точное наблюдение было у моего друга по поводу Пьера Безухова в «Войне и мире»: разницы между «хорошими» Ростовыми и «плохими» Курагиными нет, и те и другие хотят от Пьера денег и хотят его использовать. Маркер заключен только в авторской позиции: Ростовы Толстому симпатичней, но характер действий в отношении Пьера Безухова у «плохих» и «хороших» принципиально ничем не различается [5].

В коллективных воспоминаниях человечества гнездятся страхи, причем страхи совершенно реальные, потому что это уже случалось - убийства, инцесты, каннибализм, наущения на убийство, стремление получить место отца и т. д. Можно взглянуть на историю, излагаемую в Библии, как на таковую, а не на темы ее интерпретации. С кем могли вступать в контакты дети Адама и Евы? Вспомним историю двух братьев - Каина и Авеля. Эти темы тщательно табуируются в человеческом опыте и культуре. Культура в данном контексте выступает как наследие, но, судя по всему, это воспоминания о реальных событиях. Генетики сейчас настаивают на концепции единой матери всего человечества, которая родилась около двухсот тысяч лет назад в Африке. Тут меня смущает географический, а не генетический фрактор. Мать одна, а отцов много. Кто эти отцы? Может быть, часть из них - дети матери, занявшие место отцов? Я не знаю. Если гипотеза генетиков неверна и на самом деле было множество матерей и отцов, то куда делось человеческое разнообразие, если по факту сейчас существует единообразие, люди великолепно понимают друг друга, но не на уровне социума, культуры или культур, а только на уровне чувств? Или же единообразие человечества видимое? Кто-то не томится чувством вины, зная обо всех преступлениях и принимая как обычный человеческий путь то, что обрести хорошее можно только вместе с плохим. Тогда путь мудрости - какое преступление он прячет? София (Мудрость), ее цена? Вспомним Метиду (Мудрость) в античной мифологии - она была проглочена Зевсом, так как Прометей предсказал тому, что сын, рожденный от Метиды, свергнет Зевса с престола богов.

С темой любви и красоты в античные времена работали достаточно плотно. Афродита была богиней любви и красоты в Древней Греции, но, чтобы понять смыслы, с ней связанные, нужно рассказать полную историю ее рождения, только тогда тема рождения любови и красоты будет определена смысловым контекстом.

Поведаем историю о рождении Афродиты так, как она излагалась в античный период. В основе ее история об убийстве (лишении силы) отца, совершенном сыном. Но не все так просто, если вспомнить греческие мифы. Гея (земля) изнемогает от плодоносящей силы Урана (неба) и подговаривает их совместных детей, титанов, оскопить отца. Младший из семи титанов Крон совершает это. Отсеченные серпом в форме полумесяца из «седого железа» гениталии Урана падают в море. От крови, спермы, воды, отсеченной плоти, моря и пены рождается богиня любви и красоты Афрродита (пенорожденная). Если перевести слово «афрос» - это белье перья, имеется дополнительное значение - пена. У Афродиты есть еще одно имя - Анадиомена, буквально «появившаяся 
снизу вверх». Афрродиту в свои длани восприняли Зелос (ревность) и Апатэ (обман). Как видим, в смысловом плане у греков нет никаких иллюзий: за темой любви скрывается гигантская тень - лишение мужской силы, предательство, ревность, обман, насилие, пена, кровь.

Из капель крови Урана, пролившихся на Гею, родились три эринии - Алекто (неуемная), Тисифона (мстящая за убийство), Мегера (ненавистница). Основная функция эриний - возмездие. Кроме них, от капель крови родились гиганты. У Данте, в системе христианских аллюзий, читаем: «Маячили, подобные твердыне, ужасные гиганты» [6, с. 239]. В руке одного из гигантов Данте с Вергилием спускаются на самый низкий уровень Ада, где утрачена любовь. «Но он легко нас опустил в провал, где поглощен Иуда тьмой предельной» [там же, с. 242]. И. А. Ефрремов в «Туманности Андромеды» обыгрывает тему Киприды (еще одно имя Афродиты) как рожденной из пены моря и света звезд, т. е. в предельно смягченном варианте и с искусственно вводимой смысловой неточностью, связывающей рождение Афрродиты со светом звезд, а не с движением снизу вверх. По всей вероятности, Ефремову очень хотелось забыть подлинную историю рождения Афродиты. После оскопления Урана Гея сама начинает рожать детей без участия мужского начала, у нее получаются чудовища.

Необходимо уточнить, откуда взялся Уран. Читаем у Гесиода в «Теогонии»: «Гея же прежде всего родила себе равное ширью Звездное Небо, Урана, чтоб точно покрыл ее всюду» $[7$, с. 5], т. е. Уран - сын Геи. Не отсюда ли образ звезд у Ефремова? После этого Уран как самостоятельная сущность в греческих мифах не рассматривается. Он где в Тартаре? Или остался бесплодным небом, или исчез? Мы можем вспомнить фрормулу для умерших, которую запоминали греки, чтобы правильно вести себя в Аиде. Душа человека иссыхает и томится жаждой, но ей нельзя пить из Леты (реки забвения). Если выпить из Леты, душу ждет полное забвение, нужно найти источник Мнемозины (памяти). Источник охраняют стражи. Формула, при помощи которой пускают к источнику, звучит так: «Я сын Тучной (земля Гея?) и Частозвездного (небо Уран?), имя мне Астерий (светлый, звездный), душа моя иссохла, пустите меня к источнику Мнемозины». После нескольких глотков из источника душа вспоминает все. Что тогда мы боимся вспомнить, если фрормула возвращения памяти говорит о земле и небе в их целостности?
Нужно напомнить, что оскопить Урана своих детей подговаривает Гея. Крона также оскопляет его сын Зевс. Потом Зевс совокупляется со своей матерью Реей в фрорме змея. Кадуцей Гермеса (бога мудрости и проводника в царство мертвых) изображает не просто совокупляющихся змей, а Зевса с Реей. Про Кроноса нам говорят, что он жив и находится в Тартаре, который охраняют сторукие (полностью порождения Геи). Потом происходит непонятный бунт сторуких, олимпийцам победить помогают титаны (заключенные помогают своим тюремщикам, а точнее, отцы своим детям), потом титаны оказываются в Элизиуме. Про это мы знаем потому, что Элизиум еще и обитель героев, не возвращающихся из Аида, но и не попавших в Аид. На вопрос, где титаны, нам отвечают, что они спят в Элизиуме. Кто знает...

Еще один смысл связан с выражением иерархических структур. Миф сообщает нам о том, что Гея порождает равного себе мужа, который покрывает ее повсюду, но у Геи в ее глубинах скрывается Аид, а еще ниже Тартар, а еще ниже - корни земли и неба (тонкие-претонкие), которых боятся и перед которыми трепещут Боги [8, с. 36]:

Там и темной Земли, и туманного Тартара,

И неистощимого Моря, и звездного Неба

- Всех подряд - находятся истоки и концы

Страшные, затхло-гнилые, они внушают жуть даже богам.

Тогда тема страха - единственное, что спасает смысл, даже не страх, а трепетание; по сути дела, снова работает тема неосознанности. Но тогда, по этой же логике, и в небе есть небо (аллюзия подобного плана встречается у китайского мудреца Чжуанцзы). У Урана, по логике подобия и распространения (характерной для мифологического сознания), должно быть еще два неба, эквивалентных Аиду и Тартару. Где они? Как называются? Какие они?

Закон появляется тогда, когда раскрывается насилие. Точнее, закон оптимизирует насилие, переводя его в четкую структуру, а не в разлитое состояние войны всех со всеми. Это порядок социального. Но ненависть основа насилия.

Разберем библейский вариант творения. Адам - красная глина, т. е. земля, Ева жизнь. Тут используется странная логика (культурного кода): мужское не покрывает, а покрывается. Тогда Адам - мужчина? А Ева - женщина? Или наоборот? Сбито или специально спутано понятие верха и низа? Идут два параллельных библейских рассказа: 
1) мужчину и женщину сотворил; 2) потом женщина, созданная из ребра мужчины. Где тема верха и мужчины? Кто тогда мужчина и где этот мужчина? Космических стихий, как у греков, нет. Идет тема знания через наименование в соответствии с сущностью, что не спасает прародителей человечества от первородного греха. Самое основное, критическую зону, где находится грех, Адам не может определить, и именно в ней следует покорно за Евой. Тогда кто Ева - мужчина, искуситель, носительница греха, женщина? Как в отношении Евы работает тема знания и познания, в которой, как в системе знания и познания сущностей в форме истинных имен, вроде бы специалистом является Адам? Нового качества знания не достигнуто. Тогда жизнь может быть определена только в терминах непонимания. Тогда что было в начале вместо жизни? Если ввести в рассказ Лилит, то возникает другой порядок символического. Она прекрасновласая, а волосы - символ женской силы. Выходит, с Лилит связано «демоническое» в человечестве, а с Евой - человеческое «греховное» жизненное? Возникает ряд вопросов, на которые нет ответа из самой специфики и закрытости темы. В истории человеческих обществ постоянно присутствует не только тема инцеста, но и тема каннибализма. Убил ли Каин Авеля или он убил еще и Адама? Или оба брата убили отца, принесли его в жертву и съели, а потом блудили с матерью? Тогда это тема другого человечества или того же самого? Следуя логике отцовства и не заходя в крайности, мы должны признать, что есть сыны и дочери Адама, есть сыны и дочери Каина, есть сыны и дочери Авеля, но кто их матери? Что сделал Каин со своим братом? Но в результате на Каина наложен знак Бога, защищающий его от других людей. Если вспомнить мифологию, одинаково ли в смысловом плане выглядят - сын Адама от кого? И сын Каина от Евы? Адам, возможно, был убит и съеден, Авель убит и съеден, единственная женщина - Ева, кто оставшийся в живых мужчина - Каин? Тогда что Ной знает про наказание и за что Бог шлет потоп? В Ветхом Завете присутствует несколько весьма странных тем про ангелов, соединяющихся с человеческими дочерями, и совершенно непонятная тема исполинов. Запреты, введенные человечеством, позволяют прикрыть эти темы, но в истории человечества были убийства, было насилие, были инцесты, кровосмешения. Тогда, может, стоит отдавать себе отчет, что мы потомки такого человечества и обратная сторона вещей всегда будет проскальзывать и появляться в нашем опыте? Возможно, ее стоит признать, чтобы не повторять и не стоять вечно за занавеской? Высшие достижения человеческого духа могут прорасти только из удобренной почвы (земли и неба).

Тогда здесь мы можем наблюдать язык, который используют для сохранения тайн. Что это за язык? По сути дела, платят за знание языка, а не за использование, возникает тема скрытого знания.

Можно обратить внимание на одежду некоторых современных людей, одежду, которая делает их похожими на зверей. Подчеркиваются совсем не тотемные качества и характеристики, а звериная основа. Медведь не просто широкомордый, а агрессивный и разрушающий, зайка не только миленький, но и похотливый. Зверосущности. Подчеркнем еще раз: это не тотем, а основа. У Гегеля дано очень четкое определение основы: «Существование есть и рефрлектированная непосредственность основы. Основа идет как тождественная. Тождество внутреннего и внешнего - это основа, безразличная к различию этих определений как к внешней ей форме, иначе говоря, тождество как содержание» $[9$, с. 168-169].

У 3. Фрейда в книге «Тотем и табу» читаем: «По причинам, которые станут ясны ниже, я предпочитаю здесь описание S. Reinach, который в 1900 г. сделал набросок следующего Code du totemisme в 12 параграфрах, являющегося как бы катехизисом тотемистической религии:

1. Нельзя ни убивать, ни есть определенных животных, но люди воспитывают отдельных животных этого рода и ухаживают за ними.

2. Случайно погибшее животное оплакивается и хоронится с такими же почестями, как соплеменник.

3. Иногда запрещение употреблять в пищу относится только к определенной части тела животного.

4. Если под давлением необходимости приходится убить животное, которое обыкновенно нужно щадить, то перед ним надо извиниться, постараться ослабить нарушение табу убийства разнообразными искусственными приемами и оправданиями.

5. Если животное приносится в жертву по ритуалу, то его торжественно оплакивают.

6. В некоторых торжественных случаях, В религиозных церемониях надевают шкуры определенных животных. Там, где тотемизм еще сохранился, это - шкуры животного тотема. 
7. Племена или отдельные лица называются именами животных, именно животных тотема.

8. Многие племена пользуются изображением животных как гербом и украшают им свое оружие; мужчины рисуют изображение тотема на своем теле или татуируют его изображение на коже.

9. Если тотем принадлежит к страшным или опасным животным, то предполагается, что оно щадит членов названного его именем племени.

10. Животное тотем охраняет и предупреждает об опасности лиц, принадлежащих к племени.

11. Животное тотем возвещает своим поклонникам будущее и служит им вождем.

12. Члены племени одного тотема часто верят в то, что связаны с животным тотема узами общего происхождения» [10, с. 262].

Из этих определений совершенно понятно, что речь идет не о тотеме и табу, а о чемто совершенно другом, об основе, тогда как происходит подмена сущностных оснований. Выдающийся фрранцузский психолог Д. Анзье отмечает: «В социальной жизни различают три больших вида систем:

- мифология (Идеал-Я)

- утопия (Я идеальное)

- идеология (Сверх-Я)» [11, с. 64].

Ключевое основание для понимания этих систем - указание Анзье на то, что они относятся к социуму. Если социальность не оформлена, мы бродим среди основ и легко можем наткнуться на сущности, где весь ход вещей подчиняется другому порядку. Может быть, проще следовать порядку социального, а не заходить в основы, которые могут оказаться совершенно не человеческими? В результате мы можем оказаться в мире, где мы не доросли даже до греха. Каков этот мир, думаю, совершенно понятно из приведенных рассуждений: в нем нет совести, нет переживаний, нет состояний - есть вечная данность распада и импульсов, ни одно из чувств и состояний не собрано. Искусство и культура весьма показательны, через их призму мы можем увидеть и принять мир таким, каков он есть, но только если воспринимаем целостность, а не кусочек.

\section{СПИСОК ИСПОЛЬЗОВАННОЙ ЛИТЕРАТУРЫ}

1. Сартр Ж.-П. Стена / Ж.-П. Сартр. - М. : Политиздат, 1992. - 480 с.

2. Достоевский Ф. М. Полное собрание сочинений : в 30 т. / Ф. М. Достоевский. - Л. : Наука, 1984. T. $1 .-496 \mathrm{c}$.

3. Пекуровская А. Страсти по Достоевскому: механизмы желаний сочинителя / А. Пекуровская. - М. : Новое лит. обозрение, 2004. - 608 с.

4. Топоров В. Н. Миф. Ритуал. Символ. Образ / В. Н. Топоров. - М. : Прогресс-Культура, 1995. - 624 с.

5. Толстой Л. Н. Война и мир : в 4 т. / Л. Н. Толстой. - М. : Школьная б-ка, 1961. - Т. 1-2. - 752 с.

6. Данте А. Божественная комедия / А. Данте ; пер. с итал. М. Лозинского. - М. : ТЕРРА-Книжный клуб, 2002. $-688 \mathrm{c}$.

7. Гесиод. Теогония. Труды и дни / Гесиод ; пер. В. В. Вересаева. - М. : Эллин. поэты, 1928. - 408 с.

8. Фрагменты ранних греческих философов / сост. А. В. Лебедев. - М. : Наука, 1989. - Ч. 1. - 576 с.

9. Гегель Г. В. Ф. Наука логики : в 3 т. / Г. В. Ф. Гегель. - М. : Мысль, 1971. — Т. 2. - 248 с.

10. Фрейд 3. Вопросы общества и происхождение религии / 3. Фрейд. - М. : Когито-Центр, 2016. - 446 с.

11. Анзьё Д. Мышление: от Я-кожи к Я-мыслящему / Д. Анзьё ; пер. с фр. М. С. Соловьевой. - Ижевск : Эрго, $2015-198$ с.

\section{REFERENCES}

1. Sartre Jean-Paul. Le mur. Gallimard, 1939. 241 p. (Russ. ed.: Sartr Zh. P. Stena. Moscow, Politizdat Publ., 1992. 480 p.).

2. Dostoevsky F. M. Polnoe sobranie sochinenii [Complete Set of Works]. Leningrad, Nauka Publ., 1984. Vol. 1. $496 \mathrm{p}$.

3. Pekurovskaya A. Strasti po Dostoevskomu: mekhanizmy zhelanii sochinitelya [Passions According to Dostoevsky: Mechanisms of Desire]. Moscow, Novoe literaturnoe obozrenie Publ., 2004. 608 p.

4. Toporov V. N. Mif. Ritual. Simvol. Obraz [Myth, Ritual, Symbol, Impression]. Moscow, Progress-Kul'tura Publ., $1995.624 \mathrm{p}$.

5. Tolstoy L. N. Voina i mir [War and Peace]. Moscow, Shkol'naya biblioteka Publ., 1961. Vol. 1-2. 752 p.

6. Dante A. La Divina Commedia. 1304-1321. (Russ. ed.: Dante A. Bozhestvennaya komediya. Moscow, TERRA-Knizhnyi klub Publ., 2002. 688 p.).

7. Hesiod. The Homeric Hymns and Homerica. Works and Days. The Loeb Classical Library. London, 1914. 877 p. (Russ. ed.: Gesiod. Teogoniya. Trudy i dni. Moscow, Ellinskie poety Publ., 1928. 408 p.).

8. Lebedev A. V. (ed.). Fragmenty rannikh grecheskikh filosofov [Highlights from Early Greek Philosophers]. Moscow, Nauka Publ., 1989. Pt. 1. 576 p.

9. Gegel' G. V. F. Nauka logiki [Science of Logic]. Moscow, Mysl' Publ., 1971. Vol. 2. 248 p. 
10. Freid Z. Voprosy obshchestva i proiskhozhdenie religii [Society Issues and the Origin of Religion]. Moscow, Kogito-Tsentr Publ., 2016. 446 p.

11. Anzieu Didier. Le Penser. Du Moi-peau au Moi-pensant. Paris, Dunod, 1994. 308 p. (Russ. ed.: Anzieu D. Myshlenie: of Ya-kozhi k Ya-myslyashchemu. Izhevsk, Ergo Publ., 2015. 198 p.).

\section{Информация об авторе}

Атанов Андрей Алексеевич - доктор философрских наук, профессор, заведующий кафедрой философии, Байкальский государственный университет, 664003, г. Иркутск, ул. Ленина, 11, e-mail: andy777755@mail.ru.

\section{Для цитирования}

Атанов А. А. О занавеси (скрытых смыслах) в культуре и искусстве / А. А. Атанов // Известия Байкальского государственного университета. - 2018. - T. 28, № 1. - C. 143-149. - DOI: $10.17150 / 2500-2759.2018 .28(1) .143-149$.

\section{Author}

Andrei A. Atanov - DSc in Philosophy, Professor, Head of the Department of Philosophy, Baikal State University, 11 Lenin St., 664003, Irkutsk, the Russian Federation, e-mail: andy777755@mail.ru.

\section{For citation}

Atanov A. A. Concerning the "Curtain" (Hidden Meanings) in Culture and Art. Izvestiya Baykal'skogo gosudarstvennogo universiteta $=$ Bulletin of Baikal State University, 2018, vol. 28, no. 1, pp. 143-149. DOI: 10.17150/2500-2759.2018.28(1).143-149. (In Russian). 